\title{
AVALIAÇÃO (EM ESCALA LABORATORIAL) DA APLICAÇÃO DO PROCESSO ELETROLÍTICO EM EFLUENTE DE LAGOA DE ESTABILIZAÇÃO DE ESGOTO URBANO
}

\author{
Elis Marina Turini Claro e Marcelo Henrique Otenio* \\ Embrapa Gado de Leite, Rua Eugênio do Nascimento, 610, 86360-000 Juiz de Fora - MG, Brasil
}

Edério Dino Bidóia

Instituto de Biociências de Rio Claro, Universidade Estadual Paulista Júlio de Mesquita Filho, Av. 24-A, 1515, $13506-900$ Rio

Claro - SP, Brasil

\section{Natália Maria Maciel Guerra Silva}

Departamento de Patologia Geral, Universidade Estadual do Norte do Paraná, BR 369, km 54, 86360-000 Bandeirantes - PR, Brasil Valdecir dos Santos

Serviço Autônomo de Água e Esgoto, Av. Comendador Luiz Meneghel, 992, 86360-000 Bandeirantes - PR, Brasil

Recebido em 2/3/09; aceito em 15/10/09; publicado na web em 23/2/10

\begin{abstract}
(LABORATORY SCALE) ASSESSMENT OF ELECTROLYTIC PROCESSING OF EFFLUENT FROM A URBAN SEWAGE STABILIZATION LAGOON. Physico-chemical and microbiological parameters were evaluated before and after applying an electrolytic process to effluents of a stabilization lagoon, in the presence or absence of "salt". Chlorine generation and bactericidal properties of the treatments were studied following two experiments. Effluent $\mathrm{pH}$ increased with electrolysis time. In the absence of "salt", 20 min electrolysis resulted in a COD (Chemical Oxygen Demand) reduction of 44\%, along with ca. 99.9\% (3 $\log 10 \mathrm{cfu} / \mathrm{mL}$ ) reduction in total coliforms, heterotrophic bacteria and Escherichia coli. These results indicated that the electrolytic process is a promising complementary technology to improve effluent quality for stabilization lagoons.
\end{abstract}

Keywords: electrolysis; treatment of effluent; disinfection.

\section{INTRODUÇÃO}

A grande deficiência de saneamento básico em várias regiões brasileiras, em especial de esgotamento sanitário, impõe um grande número de pessoas aos riscos de exposição direta ou indireta com água contaminada. $\mathrm{O}$ volume de esgotos sanitários lançado no solo ou em corpos d'água, em estado bruto ou insuficientemente tratado, carreia expressiva carga de organismos patogênicos excretados por indivíduos no meio ambiente. Esse quadro de deficiência da barreira sanitária tem forte influência nos indicadores de saúde. ${ }^{1}$

O interesse na desinfecção dos efluentes sanitários é cada vez maior dada a crescente deterioração das fontes de abastecimento de água para uso humano. A desinfecção dos esgotos deve ser considerada quando se pretende reduzir os riscos de transmissão de doenças infectocontagiosas. Nesse sentido, os requisitos de qualidade de uma água devem ser avaliados em função dos usos previstos para a mesma. ${ }^{2}$

$\mathrm{Na}$ maioria das estações de tratamento de esgotos sanitários do Brasil inexistem processos de desinfecção e, quando existem, dá-se comumente por meio de cloração do efluente produzido no tratamento secundário. Muitos procedimentos para desinfecção da água têm sido desenvolvidos com o objetivo de atingir padrões de qualidade sustentáveis para minimizar o impacto causado pelos efluentes no meio ambiente. . $^{2,3}$

A tecnologia eletrolítica é capaz de oxidar ou reduzir íons metálicos, íons cianeto, compostos organoclorados, hidrocarbonetos aromáticos e alifáticos e seus derivados. Neste processo, elétrons são providos diretamente ao material tratado, eliminando a necessidade da adição de substâncias redutoras ou oxidantes potencialmente tóxicas. Sua utilização tem larga importância, pois reduz a toxicidade dos efluentes através da transformação de substâncias persistentes em substâncias facilmente biodegradáveis. Dessa forma, o tratamento eletrolítico permite o aumento da eficiência do tratamento biológico convencional. ${ }^{4}$

*e-mail: otenio@cnpgl.embrapa.br
Processos eletroquímicos têm sido estudados cada vez mais para o tratamento de efluentes aquosos, apresentando algumas vantagens: facilidade de operação e automação, utilização do elétron como reagente, uso do catalisador na forma de revestimento de eletrodos metálicos e formação de espécies reativas na superfície do eletrodo, fornecendo uma alternativa promissora aos métodos tradicionais, ${ }^{5}$ além de permitir a produção de compostos desinfetantes in situ, evitando assim os problemas de estocagem e transporte de produtos químicos perigosos como, por exemplo, o cloro. ${ }^{6}$

$\mathrm{O}$ tratamento de efluentes por eletrólise vem sendo utilizado em muitas empresas e em remediação ambiental, podendo-se constatar que as características da instalação (eletrodos, corrente ou potencial aplicado, fluxo de efluente etc.) devem ser adaptadas para cada caso e tipo de efluente. Um tratamento eletrolítico que sirva para todos os tipos de efluente ou para efluentes misturados, como os provenientes de áreas urbanas, parece ser ainda um objetivo distante. Ainda assim, o estudo dos efeitos da eletrólise de efluentes é um campo de pesquisa cada vez mais explorado. ${ }^{7}$

Dentro deste contexto, este trabalho propõe avaliar em escala laboratorial o processo eletrolítico em um efluente de lagoa de estabilização de uma Estação de Tratamento de Esgoto (ETE), relacionando o tempo de exposição de corrente com os parâmetros avaliados, além de testar várias concentrações de um composto salino, buscando uma dosagem ideal para geração de cloro e desinfecção do efluente.

\section{PARTE EXPERIMENTAL}

O efluente da saída da lagoa de estabilização utilizado neste trabalho foi obtido da estação de tratamento de esgoto da cidade de Bandeirantes - Paraná, que opera com duas lagoas, uma anaeróbia e uma facultativa, operada pelo Serviço Autônomo de Água e Esgoto (SAAE).

A cidade possui redes coletoras de esgoto com $98 \%$ de tratamento do esgoto urbano. 
Os experimentos foram conduzidos nos laboratórios de análises de água e esgoto na Estação de Tratamento de Água (ETA) do SAAE, Bandeirantes - PR.

O trabalho foi dividido em duas fases e, em ambas, foram utilizados eletrodos de ferro fundido (Fe/C) sendo um cátodo e um ânodo, com 214,6 $\mathrm{cm}^{2}$ (área total), com 1,30 mm de espessura cada um e distantes $9 \mathrm{~mm}$ entre si; uma fonte de corrente contínua (Dawer, modelo FCC 3005 D) e um agitador magnético (Alphalab, modelo AA 500) conforme Figura 1, preconizado por Otenio et al. ${ }^{8}$

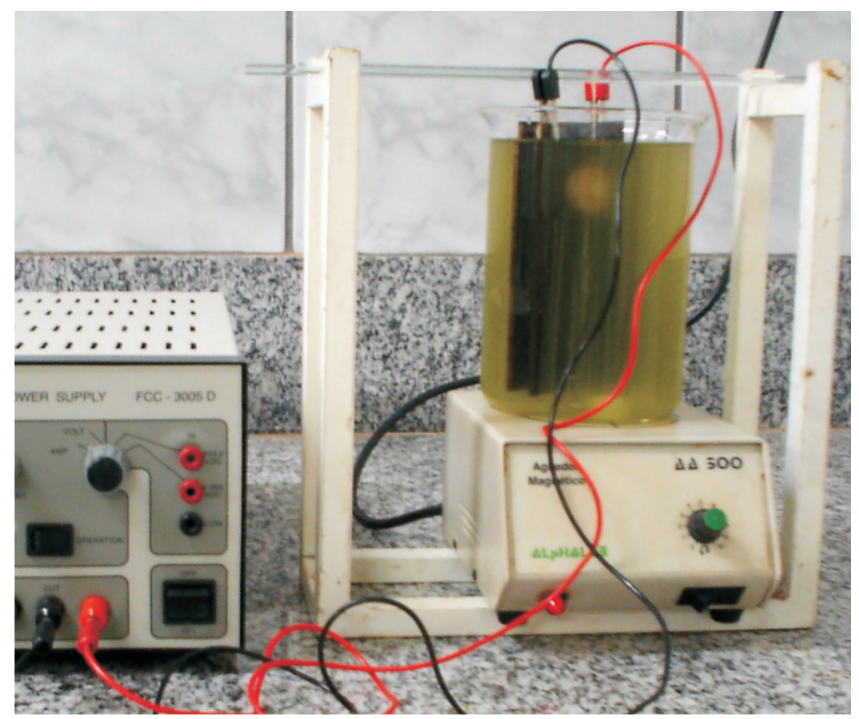

Figura 1. Equipamento: fonte de corrente contínua e aparato com eletrodos e agitadores, para rotina de aplicação do tratamento eletrolítico

Na primeira fase do estudo, foram feitas quatro repetições das análises em quatro coletas do efluente no período de maio de 2007 a junho de 2007, em 23/05, 07/06, 13/06 e 18/06. Foram coletados na saída da lagoa de estabilização da ETE $5 \mathrm{~L}$ do efluente (para cada dia de ensaio) para a realização dos experimentos. Para avaliação do efluente sem tratamento (sem adição de sal), foi utilizado $1 \mathrm{~L}$ da amostra e foi eletrolisado $1 \mathrm{~L}$ nos tempos 5, 10, 15 e 20 min em uma corrente contínua de 1,0 A (aproximadamente 33,0 V), de acordo com Otenio et al. ${ }^{8}$ sob agitação magnética constante. No primeiro ensaio, foram testados além desses, os tempos de 25 e 30 min, porém não ocorreram mudanças nos parâmetros avaliados.

$\mathrm{Na}$ segunda fase para o estudo com adição do composto salino foram feitas quatro repetições das análises em quatro coletas do efluente do efluente na saída da lagoa de estabilização da ETE. Para cada dia foram coletados $7 \mathrm{~L}$ do efluente para a realização do experimento, no período de setembro de 2007 a outubro de 2007, em 13/09, 20/09, 27/09 e 04/10.

Foi eletrolisado $1 \mathrm{~L}$ do efluente com uma corrente contínua de 1,0 A (aproximadamente 33,0 V), sob agitação magnética constante, adicionado de diferentes concentrações do composto salino (Castrolanda, composição de $6,17 \%$ de $\mathrm{NaCl}, 25 \%$ de cálcio e $3,72 \%$ de magnésio): $9,18,26,34,42$ e 50 g/L para verificar a geração de cloro residual, com tempo de tratamento fixo em $10 \mathrm{~min}$, considerado o melhor tempo de eletrólise da primeira fase. Também neste experimento foram retiradas amostras de $1 \mathrm{~L}$ para realização da análise do efluente em tempo zero (sem adição do composto salino e sem tratamento eletrolítico).

Após os diferentes tempos de eletrólise ${ }^{6,7}$ e tratamentos com e sem composto salino e realizaram-se análises físico-química e microbiológica, conforme metodologia padrão preconizada por Standard Methods for the Examination of Water and Wastewater,${ }^{9} \mathrm{CETESB}^{10-12} \mathrm{e}$ Branco. ${ }^{11}$ As amostras foram coletadas como indicado por Branco, ${ }^{11}$ para os parâmetros: demanda química de oxigênio (DQO), demanda bioquímica de oxigênio (DBO), pH, condutividade, temperatura, sólidos sedimentáveis, cor, oxigênio dissolvido (OD), fósforo total, nitrogênio total, ferro total, matéria orgânica, alcalinidade, dureza, turbidez e quantificação de bactérias heterotróficas, Escherichia coli e coliformes totais.

A análise estatística foi realizada através da média simples dos resultados em cada ponto e posteriormente tabuladas com auxílio do Programa Basic Statistic ${ }^{\circledR}, \operatorname{com} \mathrm{p}<0,05$.

\section{RESULTADOS E DISCUSSÃO}

O tratamento eletrolítico pode ser usado para diversas finalidades, a eletroxidação de matéria orgânica é uma delas. Neste processo vários parâmetros podem ser avaliados e mensurados e para melhor compreensão, os resultados das análises das duas fases foram divididos de acordo com os parâmetros.

Observou-se na primeira fase um aumento no valor do $\mathrm{pH}$ do efluente com o tempo de eletrólise de 7,6 para 8,3 (Tabela 1). Esse aumento pode ser atribuído ao consumo de prótons $\left(\mathrm{H}^{+}\right)$do efluente, decorrente da formação de hidrogênio no cátodo. ${ }^{7}$ A reação do cátodo forma hidroxilas, portanto, ocorre um aumento do $\mathrm{pH}$ do meio durante o processo eletrolítico. ${ }^{13}$

Em experimentos com eletrólise de resíduos descritos por outros autores, como de Angelis et al. ${ }^{7}$ Giordano e Barbosa Filho ${ }^{13}$ e Sinoti e Souza, ${ }^{14}$ houve tendência de elevação dos valores de $\mathrm{pH}$, constatandose assim o decréscimo da concentração de $\mathrm{H}^{+}$com o prolongamento do tempo de eletrólise para os diferentes resíduos.

Na segunda fase, utilizando-se diferentes concentrações do composto salino em 10 min de eletrólise, também ocorreu um aumento dos valores de $\mathrm{pH}$ conforme mostra a Tabela 2.

A ação da eletrólise tem uma estreita relação com a condutividade, pois quanto maior a condutividade maior será a transmissão de corrente. ${ }^{8}$ A condutividade na primeira fase apresentou um comportamento instável nos tempos analisados, diferentemente de Angelis et al. ${ }^{7} \mathrm{e}$ Bidoia e Notoya, ${ }^{15}$ onde ocorreu um aumento da condutividade com o tempo de eletrólise.

Na segunda fase, com a inclusão de eletrólitos, ocorreu aumento da condutividade conforme mostra a Tabela 2, levando à mudança de escala de medida do equipamento de $\mu \mathrm{S}$ para $\mathrm{mS}$.

Durante a eletrólise da primeira fase, foi observado um aumento da temperatura que ocorreu, provavelmente, devido à resistência do eletrodo à passagem de corrente elétrica. Como o eletrodo é coberto por uma película de óxidos, parte da corrente elétrica é mais facilmente transformada para calor, mesmo realizando-se a eletrólise sob forte agitação. ${ }^{15}$

A temperatura tem influência direta na eficiência do processo eletrolítico. Esta eficiência aumenta com o aumento da temperatura, principalmente porque as microbolhas de gás hidrogênio gerado ascendem mais rapidamente para a camada de escuma (flocos eletroflotados acumulados na superfície da camada eletrolítica). Este efeito reduz a passivação dos eletrodos e gera um consequente aumento da eficiência do processo. ${ }^{13}$

$\mathrm{O}$ aumento da cor tem correlação linear positiva com aumento do $\mathrm{pH}(0,90)$, fósforo $(0,94)$ e ferro $(0,96)$. As altas concentrações de ferro liberadas pelo eletrodo (Figura 2), em solução, tornaram a cor da solução avermelhada pelo fato dos íons $\mathrm{Fe}^{2+}{ }_{(\text {aq }}$ se oxidarem em $\mathrm{Fe}^{3+}$ (aq) levando à precipitação na forma de hidróxido de ferro III $\left(\mathrm{Fe}(\mathrm{OH})_{3}\right)$, efeito da eletrólise, o que fez com que os valores finais de cor fossem maiores do que no início.

Quanto maior for a quantidade de material em suspensão na água, mais turva ela estará. ${ }^{16}$ Segundo Sinoti e Souza, ${ }^{14}$ o eletrodo de ferro faz com que continue a produção de flocos, ou seja, ocorre evolução de bolhas de gases gerados promovendo a eletroflotação, isto é, a 
Tabela 1. Média dos resultados dos parâmetros avaliados em diferentes tempos de eletrólise do efluente da ETE de Bandeirantes, PR, no período de maio e junho de 2007 ( $1^{\text {a }}$ fase $)$

\begin{tabular}{|c|c|c|c|c|c|}
\hline \multicolumn{6}{|c|}{ Tempo (min) } \\
\hline$\underline{\text { Parâmetros }}$ & sem eletrólise & 5 & 10 & 15 & 20 \\
\hline $\mathrm{pH}$ & 7,6 & 7,9 & 8,0 & 8,3 & 8,4 \\
\hline Temperatura $\left({ }^{\circ} \mathrm{C}\right)$ & 19,0 & 19,7 & 19,9 & 20,3 & 21,0 \\
\hline Condutividade $(\mu S)$ & 531,0 & 517,5 & 527,5 & 516,5 & 518,0 \\
\hline Ferro Total (mg/L) & 0,86 & 9,6 & 24,8 & 29,4 & 48,2 \\
\hline Cor (APHA Pt/Co) & 697 & 1.395 & 1.595 & 4.170 & 3.285 \\
\hline Turbidez (UNT) & 27,8 & 58,3 & 88,3 & 83,1 & 81,3 \\
\hline Alcalinidade $\left(\mathrm{mg}\right.$ de $\left.\mathrm{CaCO}_{3} / \mathrm{L}\right)$ & 225,0 & 244,0 & 216,0 & 232,0 & 231,0 \\
\hline Dureza $\left(\mathrm{mg}\right.$ de $\left.\mathrm{CaCO}_{3} / \mathrm{L}\right)$ & 80,0 & 62,0 & 88,0 & 67,0 & 66,0 \\
\hline Fósforo $(\mathrm{mg} / \mathrm{L})$ & 0,03 & 0,05 & 0,04 & 0,09 & 0,05 \\
\hline Nitrogênio (mg/L) & 27,0 & 25,3 & 20,0 & 15,5 & 11,0 \\
\hline $\mathrm{OD}\left(\mathrm{mg} / \mathrm{L}\right.$ de $\mathrm{O}_{2}$ consumido $)$ & 2,16 & 1,73 & 1,41 & 1,19 & 1,16 \\
\hline Matéria Orgânica (mg/L de $\mathrm{O}_{2}$ consumido) & 11,0 & 10,9 & 9,9 & 11,7 & 10,3 \\
\hline Sólidos Sedimentáveis (mL/L) & 0,1 & 0,3 & 31,0 & 56,0 & 71,0 \\
\hline DQO $(\mathrm{mg} / \mathrm{L})$ & 205,25 & 198,75 & 187,75 & 133,25 & 114,75 \\
\hline $\mathrm{DBO}(\mathrm{mg} / \mathrm{L})$ & 44,1 & 55,0 & 39,3 & 42,4 & 59,8 \\
\hline Coliformes Totais (UFC/100 mL) & $9,8 \times 10^{8}$ & $2,6 \times 10^{4}$ & $6,3 \times 10^{3}$ & $1,4 \times 10^{3}$ & $63 \times 10^{1}$ \\
\hline Escherichia coli (UFC/100 mL) & $4,1 \times 10^{4}$ & $3,2 \times 10^{4}$ & $3,7 \times 10^{3}$ & $3,3 \times 10^{3}$ & $64 \times 10^{2}$ \\
\hline Bactérias heterotróficas(UFC/mL) & $2,7 \times 10^{6}$ & $7,5 \times 10^{4}$ & $4,9 \times 10^{3}$ & $2,0 \times 10^{2}$ & $18 \times 10^{1}$ \\
\hline
\end{tabular}

Obs.: Análise estatística realizada através da média simples dos resultados, com $\mathrm{p}<0,05$.

Tabela 2. Média dos resultados dos parâmetros avaliados após 10 min de eletrólise do efluente da ETE de Bandeirantes, PR, com adição de diferentes concentrações de um composto salino, no período de setembro e outubro de 2007 ( $2^{\mathrm{a}}$ fase)

\begin{tabular}{|c|c|c|c|c|c|c|c|}
\hline \multicolumn{8}{|c|}{ Concentração Salina (g/L) } \\
\hline$\underline{\text { Parâmetros }}$ & 0 & 9 & 18 & 26 & 34 & 42 & 50 \\
\hline $\mathrm{pH}$ & 7,7 & 8,9 & 8,8 & 8,7 & 9,0 & 9,0 & 8,7 \\
\hline Temperatura $\left({ }^{\circ} \mathrm{C}\right)$ & 23,5 & 22,9 & 22,4 & 22,7 & 23,2 & 22,7 & 23,2 \\
\hline Condutividade $(\mu \mathrm{S})$ & $6,50 \times 10^{2}$ & $2,30 \times 10^{4}$ & $3,70 \times 10^{4}$ & $6,08 \times 10^{4}$ & $7,94 \times 10^{4}$ & $8,83 \times 10^{4}$ & $9,99 \times 10^{4}$ \\
\hline Cor (APHA Pt/Co) & 543,0 & 391,0 & 600,0 & 525,0 & 342,0 & 510,0 & 587,0 \\
\hline Turbidez (UNT) & 24,9 & 29,4 & 30,0 & 32,4 & 28,0 & 14,3 & 45,1 \\
\hline Cloro (mg/L) & 0,0 & 0,0 & 0,0 & 0,0 & 0,0 & 0,0 & 0,0 \\
\hline DQO (mg/L) & 138 & 446 & 500 & 460 & 800 & 720 & 630 \\
\hline Alcalinidade (mg de $\left.\mathrm{CaCO}_{3} / \mathrm{L}\right)$ & 242,0 & 258,0 & 250,0 & 242,0 & 240,0 & 250,0 & 228,0 \\
\hline Dureza $\left(\mathrm{mg}\right.$ de $\left.\mathrm{CaCO}_{3} / \mathrm{L}\right)$ & 108,0 & 140,0 & 192,0 & 198,0 & 220,0 & 300,0 & 280,0 \\
\hline Fósforo $(\mathrm{mg} / \mathrm{L})$ & 0,02 & 0,0 & 0,0 & 0,0 & 0,0 & 0,0 & 0,0 \\
\hline Nitrogênio (mg/L) & 18,0 & 6,0 & 6,0 & 5,0 & 4,0 & 5,0 & 2,0 \\
\hline $\mathrm{OD}\left(\mathrm{mg} / \mathrm{L}\right.$ de $\mathrm{O}_{2}$ consumido $)$ & 1,65 & 0,28 & 0,29 & 0,0 & 0,0 & 0,0 & 0,0 \\
\hline Matéria Orgânica (mg/L de $\mathrm{O}_{2}$ consumido) & 8,4 & 7,5 & 9,8 & 9,7 & 9,2 & 9,5 & 5,2 \\
\hline Sólidos Sedimentáveis (mL/L) & $<0,1$ & 160,0 & 150,0 & 94,0 & 62,0 & 80,0 & 84,0 \\
\hline Coliformes Totais (UFC/100 mL) & $6 \times 10^{3}$ & $1 \times 10^{3}$ & $8,3 \times 10^{4}$ & $5 \times 10^{3}$ & $8,7 \times 10^{4}$ & $1,22 \times 10^{5}$ & $1,03 \times 10^{5}$ \\
\hline Escherichia coli (UFC/100 mL) & $3 \times 10^{3}$ & $11 \times 10^{3}$ & $6 \times 10^{3}$ & $1 \times 10^{3}$ & $27 \times 10^{3}$ & $2 \times 10^{3}$ & $1 \times 10^{3}$ \\
\hline Bactérias heterotróficas (UFC/mL) & $1,43 \times 10^{5}$ & $3,92 \times 10^{5}$ & $4,3 \times 10^{4}$ & $6,7 \times 10^{4}$ & $3,6 \times 10^{4}$ & $1,34 \times 10^{5}$ & $1,78 \times 10^{5}$ \\
\hline
\end{tabular}

Obs.: Análise estatística realizada através da média simples dos resultados, com $\mathrm{p}<0,05$.

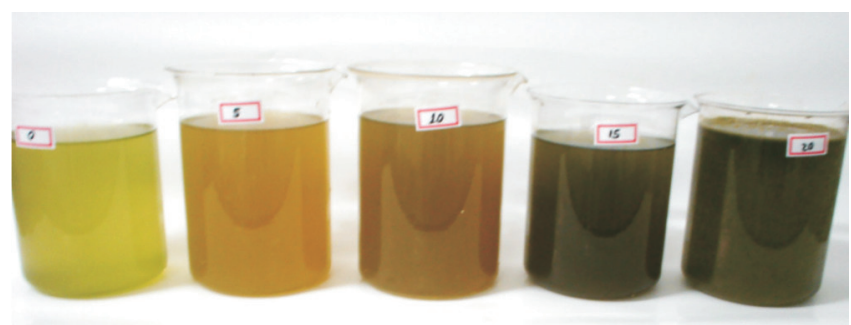

Figura 2. Variações de cor em função do tempo, devido à oxidação do ferro do eletrodo em $\mathrm{Fe}^{3+}$ de cor avermelhada. Da esquerda para a direita: tempo de eletrólise 0, 5, 10, 15 e $20 \mathrm{~min}$, sem adição do composto salino, nos períodos de maio e junho de 2007

ascensão de flocos formados por eletrocoagulação, aumentando assim a turbidez (Tabela 1). Os sólidos sedimentáveis foram diretamente proporcionais ao teor de ferro $(0,96)$.

Na segunda fase, em 10 min de eletrólise com diferentes concentrações do composto salino, não ocorreu grande diferença na cor e na turbidez após a eletrólise. Houve formação do ácido hipocloroso que reagiu com $\mathrm{OH}^{-}$, não formando $\mathrm{Fe}(\mathrm{OH})_{3}$ de cor vermelha, mas possivelmente formando $\mathrm{FeCl}_{2} \mathrm{ou} \mathrm{Fe}(\mathrm{OH})_{2}$ de cor branca. A formação de $\mathrm{Cl}_{2}$ na presença de $\mathrm{NaCl}$ pode levar à diminuição da formação de $\mathrm{O}_{2}$ no ânodo, e isto reduz a formação de $\mathrm{Fe}^{3+}$.

A dureza é a concentração de cátions metálicos divalentes em solução. Os cátions mais frequentemente associados à dureza são os cátions bivalentes $\mathrm{Ca}^{2+} \mathrm{e} \mathrm{Mg}^{2+}$. Em condições de supersaturação, esses cátions reagem com ânions na água, formando precipitados. ${ }^{17}$ Os valores de remoção de dureza foram de 17,5\% em $20 \mathrm{~min}$ de eletrólise (Tabela 1).

$\mathrm{Na}$ eletrólise com o composto salino (Tabela 2), ocorreu um aumento gradativo e considerável do parâmetro dureza devido à existência de $\mathrm{Ca}^{2+} \mathrm{e} \mathrm{Mg}^{2+}$ na mistura salina utilizada (25\% de cálcio e $3,72 \%$ de magnésio).

Os valores da alcalinidade não apresentaram variação no decorrer do tempo de eletrólise (Tabelas 1 e 2). A alcalinidade é a capacidade que as águas têm de neutralizar os ácidos. A alcalinidade é causada por sais alcalinos principalmente sódio e cálcio, sua importância é 
relevante no processo de floculação das águas, quando da utilização de floculantes como sulfatos de alumínio. Os resultados encontrados revelam que a eletrólise não aumenta a alcalinidade e esta é inversamente proporcional à dureza $(-0,93)$.

O nitrogênio total reduziu $25,9 \%$ em 10 min de eletrólise atingindo $20 \mathrm{mg} / \mathrm{L}$, conforme mostra a Tabela 1, enquadrando o lançamento às exigências da Resolução $\mathrm{N}^{\circ} 357$ do CONAMA, ${ }^{18}$ cujo padrão de emissão é de $20 \mathrm{mg} / \mathrm{L}$ de nitrogênio. Os tempos anteriores excediam os valores permitidos para o lançamento. Verificou-se estatisticamente que o nitrogênio é diretamente proporcional à $\mathrm{DQO}(0,97)$ e inversamente proporcional ao ferro $(-0,98)$ e aos sólidos sedimentáveis $(-0,99)$.

O nitrogênio, dentro do ciclo na biosfera, se alterna entre várias formas e estados de oxidação. No meio aquático, o nitrogênio pode ser encontrado nas seguintes formas: nitrogênio molecular $\left(\mathrm{N}_{2}\right)$, escapando para a atmosfera; nitrogênio orgânico (dissolvido e em suspensão); amônia (livre $\mathrm{NH}_{3}$ e ionizada $\mathrm{NH}_{4}^{+}$); nitrito $\left(\mathrm{NO}_{2}^{-}\right)$e, nitrato $\left(\mathrm{NO}_{3}^{-}\right){ }^{-17}$

Espécies nitrogenadas, como a amônia, são removidas pela constante aeração e produção de gases na eletrólise. Isto explica a diminuição de nitrogênio à medida que o tempo de eletrólise aumenta.

Ao realizar a eletrólise na segunda fase, com adição do composto salino, ocorreu uma diminuição considerável do nitrogênio, $88,8 \%$ de redução com $50 \mathrm{~g}$ da mistura salina, porém os valores de nitrogênio para todas as concentrações salinas estão dentro dos padrões permitidos para lançamento; entretanto, todas essas concentrações salinas utilizadas são inadequadas para lançamento segundo a Resolução $\mathrm{N}^{\circ} 357$ do CONAMA. ${ }^{18}$

Segundo Metcalf e Eddy, ${ }^{19}$ dentre as formas de fosfato usualmente encontradas em soluções aquosas, estão o ortofosfato, o polifosfato e o fosfato orgânico.

Para remoção significativa de fósforo, são necessárias condições de $\mathrm{pH}$ relativamente elevado; comparando-se com o nitrogênio esta dependência é mais importante. O pH deve estar em no mínimo 9,0 para que haja uma precipitação significativa de fósforo. ${ }^{20}$

A lagoa de estabilização estudada não apresenta $\mathrm{pH}$ suficientemente elevado para que ocorra a precipitação do fósforo (efluente sem tratamento eletrolítico). Após o tratamento eletrolítico, o fósforo não variou sua concentração devido ao $\mathrm{pH}$ máximo ter sido 8,4 com 20 min de eletrólise. Entretanto, com a adição de 9 g do composto salino nas amostras do efluente para eletrólise, obteve-se remoção total de fósforo. Segundo Metcalf e Eddy ${ }^{19}$ a remoção do fósforo do esgoto sanitário ocorreu através da adição da mistura salina que reagiu com o fosfato, formando um precipitado sendo removido juntamente com o lodo biológico.

O fósforo é considerado como o nutriente de maior importância nos fenômenos de eutrofização e tem sido o foco das atenções para a melhoria da qualidade dos corpos d'água. ${ }^{21} \mathrm{~A}$ remoção do fósforo é importante para evitar a proliferação de algas e plantas aquáticas.

A DQO indica a quantidade de oxigênio que seria consumida através da oxidação não biológica de compostos orgânicos presentes no efluente; assim, a DQO está diretamente correlacionada à quantidade de matéria orgânica presente no efluente eletrolisado. ${ }^{7}$ Conforme mostra a Tabela 1, com 20 min de eletrólise, houve uma diminuição da DQO em 44\%. Essa redução no valor da DQO indica que a eletrólise é eficaz na redução da matéria orgânica.

O método para a determinação da DQO recomenda ausência de $\mathrm{Fe}^{2+}$, pois estes interferem no teste oxidando o reagente dicromato de potássio. ${ }^{7}$ Entretanto, a amostra do resíduo eletrolisado para o teste de DQO foi altamente aerada, com agitação vigorosa, o que garantiu que contivesse somente $\mathrm{Fe}^{3+}$, que não interferem no teste da DQO por esses cátions estarem em seu estado máximo de oxidação.

A DQO das amostras do efluente com diferentes concentrações do composto salino foi realizada, porém, devido à alta concentração de cloretos que interferem na análise ${ }^{15}$ os resultados não foram conclusivos.
O efluente eletrolisado com $20 \mathrm{~min}$ apresentou $71 \mathrm{~mL} / \mathrm{L}$ de sedimentos (Tabela 1) ao passo que o efluente eletrolisado durante a metade do tempo (10 min), mas com adição de $18 \mathrm{~g}$ do composto salino apresentou $150 \mathrm{~mL} / \mathrm{L}$ de sedimentos (Tabela 2) No efluente não eletrolisado, essa sedimentação foi menor que $0,1 \mathrm{~mL} / \mathrm{L}$, como mostra a Tabela 1.

Sob a ação da eletrólise, a matéria orgânica é floculada por interagir com os íons $\mathrm{Fe}^{3+}$ produzidos, aumentando a quantidade de sólidos sedimentáveis, removendo dessa forma a matéria orgânica dissolvida e em suspensão. Consideram-se como sólidos sedimentáveis aqueles capazes de sedimentar no período de $1 \mathrm{~h}^{17}$

Um parâmetro importante para avaliação de efluentes é a DBO, que indica a quantidade de oxigênio consumida na oxidação bioquímica da matéria orgânica no efluente, bem como a oxidação de espécies nitrogenadas e algumas espécies redutoras $\left(\mathrm{Fe}^{2+}, \mathrm{S}^{2-}\right.$ etc). Mas neste experimento não houve alteração significativa nos valores de DBO após a aplicação da eletrólise, sendo que a média foi 48,12 $\mathrm{mg} / \mathrm{L}$ e o desvio padrão 8,80 .

Quanto ao oxigênio dissolvido, este diminuiu, chegando e mantendo-se $0 \mathrm{mg} / \mathrm{L}$ (zero) a partir da adição de $26 \mathrm{~g} / \mathrm{L}$ do composto salino (Tabela 2), isto ocorrido para a estabilização da matéria orgânica e devido às reações do ânodo não formarem $\mathrm{O}_{2}$ e $\operatorname{sim} \mathrm{Cl}_{2}$. Com o gás hidrogênio evoluindo no cátodo, arrasta o $\mathrm{O}_{2}$ para fora da solução reduzindo sua concentração. A oxidação que ocorreu dos íons $\mathrm{Fe}^{2+}$ para $\mathrm{Fe}^{3+}$ também consumiu o $\mathrm{O}_{2}$.

Um dos objetivos da proposta desse tratamento eletrolítico foi a substituição do cloro gás no pós-tratamento de efluentes, pelo composto salino, para geração de cloro e posterior desinfecção do efluente.

Os resultados do teste de contagem microbiana indicaram que durante o processo eletrolítico ocorreu diminuição de coliformes no efluente. A Tabela 1 mostra que ocorreu uma redução percentual de unidades formadoras de colônias de bactérias coliformes totais e bactérias heterotróficas de 99,9 e 98,4\% de Escherichia coli. Angelis et al. ${ }^{7}$ constataram a morte de $100 \%$ de bactérias após 30 min de eletrólise, porém, seu experimento envolvia uma carga microbiana inicial menor que a do presente estudo.

De acordo com Angelis et al., ${ }^{7}$ a morte dos microrganismos bacterianos dá-se, principalmente, devido às propriedades redutoras do íon ferroso: a difusão do íon ferroso para o seio da solução permite que entre em contato com a parede celular do microrganismo, o que causa eletroporação. Tolentino-Bisneto e Bidóia ${ }^{22}$ trabalharam com a eletrólise de Bacillus subtilis e observaram que as células ficavam com material de lise e tamanho comum reduzido, além de também ter sido observado um extravasamento do citoplasma. Após $30 \mathrm{~min}$ de eletrólise, a parede das células apresentou buracos e parte do citoplasma escoou como resultado da eletroporação irreversível.

A eletrólise com o composto salino leva à formação de cloro, que tem como utilidade ação desinfetante. Ele é ativo como bactericida por sua ação oxidante. Nesse trabalho, após a eletrólise, não se obteve residual de cloro nas amostras (Tabela 2). Este fato pode ter ocorrido pela quantidade alta de matéria orgânica no efluente, onde todo o cloro gerado estaria oxidando a matéria orgânica, tornando-se indisponível, portanto, como cloro residual para destruição microbiana.

Neste estudo, a enumeração bacteriana do efluente eletrolisado com adição do composto salino indica que este tratamento não reduz a população bacteriana. Assim, a ação do composto salino como bactericida não foi eficaz (Tabela 2). A quantidade mínima utilizada para o teste de eletrólise ( $9 \mathrm{~g} / \mathrm{L})$ já não se enquadra nos padrões de lançamento da Resolução $N^{\circ} 357$ do CONAMA $;{ }^{18}$ por exceder os valores permitidos para concentração salina, não houve consumo ou reação suficiente desta mistura salina para formação de cloro, como esperado.

Não houve significância estatística para os parâmetros microbiológicos. 


\section{CONCLUSÕES}

Os resultados obtidos indicaram que o processo eletrolítico, nas condições operacionais estudadas, além de possuir potencial para novas pesquisas é uma tecnologia complementar promissora no tratamento de efluentes. O uso de processos eletroquímicos isoladamente ou em conjunto a outros tipos de tratamento é viável tecnicamente.

A utilização de eletrodos de ferro causou a liberação de íons ferro no efluente, pela dissolução dos eletrodos durante a eletrólise. Essa liberação não acarreta problemas ambientais desde que a corrente, os eletrodos e o tempo de residência sejam dimensionados de forma adequada. Por outro lado, na primeira fase, os íons $\mathrm{Fe}^{2+}$ inicialmente liberados causam a morte de microrganismos e, ao se oxidarem a $\mathrm{Fe}^{3+}$, contribuem para a floculação e sedimentação dos resíduos sólidos.

O tempo de eletrólise ideal para a realização do polimento do efluente foi $10 \mathrm{~min}$, tempo que apresentou os melhores resultados dos parâmetros avaliados de grande importância ambiental, sendo este o melhor processo para o polimento do efluente.

O tratamento eletrolítico com adição do composto salino obteve resultados mais expressivos como polimento na concentração de $34 \mathrm{~g} / \mathrm{L}$, porém, essa concentração não se enquadra nas exigências da Resolução $\mathrm{N}^{\circ} 357$ do CONAMA, ${ }^{18}$ onde o máximo permitido para águas doces de cloreto total é de $250 \mathrm{mg} / \mathrm{L}$. Os resultados e as concentrações salinas interessam sob o ponto de vista de pesquisa pura, o que pode auxiliar a abertura de outras linhas de pesquisa e eventual mudança na legislação, precipitando alto impacto aplicado.

Para os parâmetros microbiológicos, o processo eletrolítico sem adição do composto salino foi mais eficaz sendo que, com adição deste, não ocorreu diminuição das colônias bacterianas, devido a alta quantidade de matéria orgânica. A adição do composto salino para geração de bactericida não se mostrou eficaz.

As eficiências de remoção de fósforo foram satisfatórias. A remoção do fósforo é importante por prevenir a eutrofização dos corpos hídricos receptores, evitando a proliferação de algas e plantas aquáticas.

A implantação do processo eletrolítico pode ser efetiva com pequena modificação numa estação de tratamento físico-químico tradicional; sem demandar área significativa; aproveitando os equipamentos existentes; podendo realizar tratamento contínuo ou em bateladas; sem a necessidade de investimentos elevados.

A aplicação do processo eletrolítico aqui apresentado pode ser considerada como uma proposta de tratamento terciário, guardando algumas considerações, para o efluente de lagoa de estabilização.

\section{AGRADECIMENTOS}

Ao Serviço Autônomo de Água e Esgoto (SAAE) de Bandeirantes - Paraná - Brasil

\section{REFERÊNCIAS}

1. Gonçalves, R. F.; Desinfecção de Efluentes Sanitários, Abes: Vitória, 2003.

2. Lapolli, F. R.; Hassemer, M. E. N.; Camargo, J. G.; Damásio, D. L.; Lobo-Recio, M. A.; Eng. Sanit. Ambient. 2005, 10, 200.

3. http://www6.ufrgs.br/ltm/attachments/115_Fabiana.pdf, acessada em Janeiro 2010.

4. Régis, G.; Bidóia, E. D.; Arq. Inst. Biol. 2004, 71, 299.

5. Fornazari, A. L. T.; Malpass, G. R. P.; Miwa, D. W.; Motheo, A. J.; $2^{\text {nd }}$ International Workshop - Advances in Cleaner Production, São Paulo, Brasil, 2009.

6. Ribeiro, M. A.; Guerra, N. M. M.; Bidoia, E. D.; Arq. Inst. Biol. 2004, $71,255$.

7. Angelis, D. F.; Corso, C. R.; Bidóia, E. D.; Moraes, P. B.; Domingos, R. N.; Rocha-Filho, R. C.; Quim. Nova 1998, 21, 20.

8. Otenio, M. H.; Panchoni, L. C.; Cruz, G. C. A.; Ravanhani, C.; Bidoia, E. D.; Quim. Nova 2008, 31, 508.

9. Clesceri, L. S.; Greenberg, A. E.; Trussell, R. R.; Franson, M. A. H.; Standard Methods for the Examination of Water and Wastewater, $20^{\text {th }}$ ed., Apha: Washington, 2000.

10. Funasa; Manual técnico de análise de água para consumo humano, Departamento de Saneamento: Brasília, 1999.

11. Branco, S. M.; Hidrobiologia Aplicada à Engenharia Sanitária, $2^{\mathrm{a}}$ ed., Bnh/Abes/Cetesb: São Paulo, 1978.

12. Cetesb; Contagem Padrão de Colônias de Bactérias, Bnh/Abes/Cetesb: São Paulo, 1986, (Norma Técnica L5.201).

13. Giordano, G.; Barbosa Filho, O.; Anais do XXVII Congresso Interamericano de Engenharia Sanitária e Ambiental, Porto Alegre, Brasil, 2000.

14. Sinoti, A. L. L.; Souza, M. A. A. de.; Anais do XXIII Congresso Brasileiro de Engenharia Sanitária e Ambiental, Campo Grande, Brasil, 2005.

15. Bidóia, E. D.; Notoya, E. Y.; Arq. Inst. Biol. 2004, 71, 295.

16. Hermes, L. C.; Silva, A, A. S.; Avaliação da qualidade das águas, $21^{\mathrm{a}}$ ed., Embrapa: Jaguariúna, 2004.

17. von Sperling, M.; Princípios do tratamento biológico de águas residuárias: introdução à qualidade das águas e ao tratamento de esgotos, $3^{\mathrm{a}}$ ed., UFMG: Belo Horizonte, 2006.

18. BRASIL. Conselho Nacional do Meio Ambiente; Resolução CONAMA $n^{\circ}$ 357, de 17 de março de 2005, Brasília, 2005.

19. Metcalf, A.; Eddy, S.; Wasterwater engineering - Treatment, disposal and reuse, $4^{\mathrm{a}}$ ed., Macgraw-Hill: Nova York, 2003.

20. von Sperling, M.; Princípios do tratamento biológico de águas residuárias: Lagoas de estabilização, $2^{\mathrm{a}}$ ed., UFMG: Belo Horizonte, 2002.

21. Chao, I. R. S.; Morita, D. M.; Ferraz, T. H.; Anais do XXIII Congresso Brasileiro de Engenharia Sanitária e Ambiental, Belo Horizonte, Brasil, 2007.

22. Tolentino-Bisneto, R.; Bidóia, E. D.; Braz. J.Microbiol. 2003, 34, 48. 